\title{
In Vitro Immunomodulatory Effect of Food Supplement from Aloe vera
}

\author{
Zaira López $\mathbb{D}^{1},{ }^{1}$ Antoni Femenia, ${ }^{2}$ Gabriela Núñez-Jinez $\mathbb{D}^{1},{ }^{1}$ Michelle N. Salazar Zúñiga, \\ M. Eduardo Cano, ${ }^{3}$ Teresa Espino, ${ }^{4}$ and Peter Knauth $\mathbb{( i )}^{1}$ \\ ${ }^{1}$ Cell Biology Laboratory, Centro Universitario de la Ciénega, Universidad de Guadalajara, \\ Av. Universidad 1115, 47810 Ocotlán (Jal.), Mexico \\ ${ }^{2}$ Department of Chemistry, University of Balearic Islands, Ctra. Valldemossa km 7.5, 07122 Palma de Mallorca, Spain \\ ${ }^{3}$ Laboratorio de Biofísica, Centro Universitario de la Ciénega, Universidad de Guadalajara, \\ Av. Universidad 1115, 47810 Ocotlán (Jal.), Mexico \\ ${ }^{4}$ Laboratorio de Química, Centro Universitario de la Ciénega, Universidad de Guadalajara, \\ Av. Universidad 1115, 47810 Ocotlán(Jal.), Mexico
}

Correspondence should be addressed to Peter Knauth; knauth@gmx.de

Received 8 November 2018; Revised 28 January 2019; Accepted 3 February 2019; Published 3 March 2019

Academic Editor: Ian Cock

Copyright (C) 2019 Zaira López et al. This is an open access article distributed under the Creative Commons Attribution License, which permits unrestricted use, distribution, and reproduction in any medium, provided the original work is properly cited.

\begin{abstract}
Food industries typically use Aloe vera as concentrated $(100 \times$ to $200 \times)$ and dried powders in their final products. These powders are obtained by extrusion of Aloe inner leaf gel (ILG) or Aloe whole leaf (WLP); the juice is filtered through diatomaceous earth and activated carbon before spray drying at temperatures below $70^{\circ} \mathrm{C}$. In another process, Aloe inner leaf gel was dried at $\sim 80{ }^{\circ} \mathrm{C}$ and mashed to a powder rich in high molecular weight fibres and soluble polysaccharides (ILF). In contrast to ILG and WLP, the ILF sample was cytotoxic for the human intestinal cell line Caco-2 $\left(\mathrm{CC}_{50}=1 \mathrm{~g} / \mathrm{l}\right)$, even at concentrations below the recommended dose for human consumption. At lower concentrations $(250 \mathrm{mg} / \mathrm{l})$ with LPS challenged macrophage-like THP- 1 cells decreased by $40 \%$ the release of the anti-inflammatory cytokine IL-10, whereas the release of the proinflammatory cytokine IL- $1 \beta$ increased by $35 \%$ (compared to untreated but challenged macrophage-like THP-1 cells). Unexpectedly, under the same conditions, the less cytotoxic ILG and WLP, both samples with a lower fibre content, significantly increased (up to 2.4 times) the release of IL-10, while the concentration of IL- $1 \beta$ remained unaltered and of TNF $\alpha$ decreased by $35 \%$. Even more interesting is that a treatment of the ILF sample with activated carbon reduced its cytotoxicity and increased the IL-10 release (3.1 times). Based on these results, we suggest applying an activated carbon treatment on Aloe-starting products, which have high fibre content and have received high temperature treatment, in order to reduce their cytotoxicity and improve their immunomodulatory properties.
\end{abstract}

\section{Introduction}

The biological activities of raw extracts from Aloe vera have been the object of a broad variety of studies. Among the most interesting effects are induction of apoptosis $[1,2]$, hepatoprotection [3], antioxidant $[4,5]$, antibacterial $[6$, $7]$, antidiabetic [8], antihyperglycemic $[9,10]$, and antiinflammatory effects [11-14]. Such effects are attributed to more than 70 potentially bioactive compounds [15] present in the Aloe vera plant; however, these biological activities can often be attributed to a synergistic action of more than one constituent rather than to a single compound [16].
Aloe vera leaves have a waxy cuticle followed by a single cell epidermis and a thin layer of chlorenchyma cells with vascular bundles, which produce a bitter tasting exudate called Aloe latex. The central part of the leaf consists of a thick watery inner parenchyma, called Aloe fillet, and the extruded fillet is known as Aloe gel. Most Aloe vera-containing food products are made with Aloe gel, because it lacks a series of secondary metabolites of the Aloe latex such as glycosylated anthrones (e.g., aloin) and nonglycosylated anthraquinones (e.g., aloe emodin), which exhibit several toxic effects $[17,18]$. Therefore, products containing more than $10 \mathrm{ppm}$ aloin are not considered as "generally recognized as safe" (GRAS) by 
the US Food and Drug Administration (FDA) [19]. The dry mass of Aloe gel is mainly composed of crude fibres $(35.5 \%)$, soluble saccharides $(26.8 \%)$, ashes $(23.6 \%)$, proteins $(8.9 \%)$, and lipids $(5.1 \%)$. The crude fibres consist of $72.2 \%$ polysaccharides, which in turn are composed mainly of mannose (52.8\%), glucose (26.7\%), uronic acids (13\%), xylose (1.4\%), and arabinose (1.2\%). In fresh Aloe gel the soluble acemannan, an acetylated polysaccharide composed of $77 \% \beta$-1,4-linkedmannosyl and $11 \% \beta$-1,4-linked glycosyl residues with $0.7 \%$ terminal galactose, can be found; additional branching points are mainly at $\mathrm{C}_{3}$ with $1.7 \%$ mannosyl and at $\mathrm{C}_{6}$ with $2.5 \%$ glycosyl and $1.6 \%$ mannosyl residues achieving an average molecular weight of $30-40 \mathrm{kDa}$ [20].

It is believed that the polysaccharides present in the Aloe gel are responsible for the immunomodulatory effects, since they can alter several interactions among cells of the immune system. When cells such as mouse RAW264.7 macrophages are exposed only to Aloe vera polysaccharides, the proinflammatory cytokine release (IL-1 $\beta$, IL-6, IL-8, and $\mathrm{TNF} \alpha$ ) increases in a dose-dependent manner [21, 22] and this activity could be attributed to the fraction with a molecular weight of $5-400 \mathrm{kDa}$ [22]. This effect may be explained by the fact that long chain acemannans $(>500 \mathrm{kDa}$ at $50 \mu \mathrm{g} / \mathrm{ml}$ ) are able to activate a $\mathrm{NF} \kappa \mathrm{B}$-reporter system in nondifferentiated human THP-1 monocytes to a similar amount as $10 \mu \mathrm{g} / \mathrm{ml}$ LPS [23]. As expected, when human peripheral blood macrophages are challenged with LPS, a proinflammatory cytokine release (IL- $1 \beta$, IL-6, IL-8, and $\mathrm{TNF} \alpha$ ) is stimulated; although, when the cells are additionally exposed to Aloe vera polysaccharides, anti-inflammatory effects could be observed, the proinflammatory cytokine release was inhibited $[12,13]$, which may be explained by an inhibition of the P2X7-receptor for exogenous ATP, which in turn inhibits the expression of the NLRP3-inflammosome. Additionally, the phosphorylation of $\mathrm{I} \kappa \mathrm{B}$, which inhibits proinflammatory $\mathrm{NF} \kappa \mathrm{B}$-signalling, is also inhibited [13]. And, furthermore, in human gingival fibroblasts Aloe vera polysaccharides are able to activate the proinflammatory TLR5-signalling [24].

As the commercialization of Aloe vera products increases, concerns arise on varying product quality even when those are certified by the International Aloe Science Council (IASC) [25]. Starting products for foodstuff from Aloe vera are usually commercialized as concentrated powders; thus, the different drying procedures applied on fresh Aloe gel can modify the molecular structure of constituents and, in particular, may affect acemannan. Regardless of the industrial process (spray drying, freeze drying, refraction window, or radiant zone drying), the molecular weight of acemannan decreased from $49 \mathrm{kDa}$ to $23-26 \mathrm{kDa}$ as did the mannose and the terminal galactose content. And, more important, the degree of acetylation of acemannan was also strongly reduced by 40 to $70 \%$. This reduction not only alters some physicochemical properties but also can affect many of the biological activities attributed to Aloe vera [26]. Furthermore, the achieved drying temperature also affects the acemannan constitution: temperatures up to $80{ }^{\circ} \mathrm{C}$ promoted an elongation of the acemannan backbone and, at the same time, increased debranching and deacetylation reactions [27]. We have already contributed to elucidate the consequences of heating processes on several Aloe vera commercial products: while a spray-dried inner leaf gel powder (ILG) was not cytotoxic to HeLa up to $12 \mathrm{~g} / \mathrm{l}$, a belt dried inner leaf powder with a high fibre and polysaccharide content (ILF) was already cytotoxic to HeLa at concentrations of $1-5 \mathrm{~g} / \mathrm{l}$, which is even below the recommended concentration for human consumption of $5 \mathrm{~g} / \mathrm{l}$ [28]. This cytotoxic effect might have been caused by an alteration of the fibres or polysaccharides due to the high temperatures applied during the drying process. Within this context, the aim of this study was to analyse the immunomodulatory effect on human macrophage-like cell line THP-1 induced by Aloe gel commercial powders. These powders, used as food supplements, were provided by Mexican facilities of a US enterprise.

\section{Materials and Methods}

2.1. Starting Products of Aloe vera. The starting products (powders) were provided by Mexican facilities of a US enterprise, which commercializes them as food supplements. On request and in order to obtain samples, the name of the enterprise can be provided. Briefly, the whole leaves were mashed, filtered and pasteurized, filtered with diatomaceous earth, decolourized with activated carbon, filtered ( $4 \mu \mathrm{m}$ pore size), and dehydrated by spray drying to a $100 \times$ whole leaf powder (WLP), which should be used at $10 \mathrm{~g} / \mathrm{l}(1 \times)$. Pasteurized inner leaf fillets were mashed, filtered with diatomaceous earth, decolourized with activated carbon, filtered $(4 \mu \mathrm{m}$ pore size), and dehydrated by spray drying to a $200 \times$ inner leaf gel powder (ILG), which mainly contains the soluble acemannan polysaccharide and should be used with $5 \mathrm{~g} / \mathrm{l}(1 \times)$. Alternatively, pasteurized inner leaf fillets were belt dried and crushed to a $200 \times$ inner leaf fibre powder (ILF), which has a high content of hardly soluble fibres, as well as the soluble acemannan polysaccharide [28].

The samples (WLP, ILG, and ILF) were dissolved by $1 \mathrm{x}$ or $5 \mathrm{x}$ in culture medium with $50 \mu \mathrm{g} / \mathrm{ml}$ gentamicin (Alexis/Enzo Life Sciences, Farmingdale, USA) and the $\mathrm{pH}$ was adjusted with $\mathrm{NaOH}$ to $\mathrm{pH} 7.3 \pm 0.1$. In order to evaluate the impact of the insoluble fibre content of the ILF-suspension, these samples were further treated to obtain a solution: (a) centrifuged for $20 \mathrm{~min}$ at 14,000 $\mathrm{g}$ (Eppendorf 5415D, Hamburg, Germany) (ILF-c) or (b) filtered through a nylon filter with $0.2 \mu \mathrm{m}$ pore size (ILF-f) or (c) $10 \mathrm{~g} / \mathrm{lLF}(2 \times)$ dissolved in phosphate buffered saline (PBS) and treated for $1 \mathrm{~h}$ with $40 \mathrm{~g} / \mathrm{l}$ activated carbon, filtered (nylon, $0.2 \mu \mathrm{m}$ pore size), and diluted 1:1 with culture medium supplemented with 20\% FBS (Biowest, Kansas City, USA) (ILF-ac).

2.2. Cell Lines and Culture Conditions. The cell lines THP-1 and Caco-2 (\#TIB-202 and \#HTB-37, both ATCC, Manassas, USA) were grown at $37{ }^{\circ} \mathrm{C}, 4 \% \mathrm{CO}_{2}$, and $95 \% \mathrm{RH}$ in DMEM/F12 (Caisson, Smithfield, USA) and DMEM (ATCC), respectively, both supplemented with $10 \%$ FBS.

For the tests, $3 * 10^{5}$ THP- 1 or $6 * 10^{4}$ Caco- 2 were seeded in $1 \mathrm{ml}$ culture medium (when necessary on cover slides) in 12-well multititre plates. For cytotoxicity studies, the human 
colon line Caco-2 was incubated for $3 \mathrm{~d}$ for attachment and to achieve a high confluence of $>90 \%$, before the medium was changed for sample-containing medium. The cells were then grown for $4 \mathrm{~h}$ or $24 \mathrm{~h}$ prior to analysis. For immunomodulatory studies, the monocyte cell line THP1 was differentiated to macrophage-like cells by adding 1 $\mu \mathrm{M}$ phorbol-12-myristate-13-acetate (PMA; Sigma-Aldrich, St. Louis, USA) and dissolved in PBS, to the culture medium, followed by incubation for $3 \mathrm{~d}$; the differentiation was checked by observing cell adherence before the medium was changed for sample-containing medium.

\subsection{Cytotoxicity: Caco-2. Metabolic activity was determined} qualitatively by neutral red uptake (NRU) and quantified using the WST-test. The sample-containing medium was removed, the cells were washed with PBS and fresh culture medium containing $20 \mu \mathrm{l} / \mathrm{ml}$ WST-1 (Clontech, Mountain View, USA) and $20 \mu \mathrm{l} / \mathrm{ml} 0.33 \%$ neutral red solution (Santa Cruz, Santa Cruz, USA), respectively, were added, and the cells were incubated for further $4 \mathrm{~h}$. For the NRU-test, cover slides were washed once with PBS and observed under the microscope (Axioskop $40 \mathrm{FL}$, Zeiss, Oberkochen, Germany). For the WST-test, $900 \mu \mathrm{l}$ medium was removed and centrifuged $(1 \mathrm{~min}, 8,000 \mathrm{~g})$ and the absorbance was measured at $\lambda=440 \mathrm{~nm}$ and $\lambda=690 \mathrm{~nm}$ (as background) (Mecasys Optizen-Pop, Daejeon, South Korea).

\subsection{Immunomodulation: THP-1. After THP-1 monocytes} were differentiated to macrophage-like cells and exposed for $1 \mathrm{~h}$ to the different samples (medium change), the cells were challenged with $1 \mu \mathrm{g} / \mathrm{ml}$ LPS (L4291, Sigma-Aldrich). After $3 \mathrm{~h}$ and $24 \mathrm{~h}$, respectively, $400 \mu \mathrm{l}$ culture medium was removed, centrifuged $(15 \mathrm{~min}, 1,500 \mathrm{~g})$, and stored at $-80{ }^{\circ} \mathrm{C}$ until further analysis. At the same time, $10 \mu$ l trypan blue was added to the residual medium and cell viability was analysed by microscopy.

2.5. Cytokine Release: TNF $\alpha, I L-1 \beta, I L-10$. The centrifuged and stored supernatants were analysed by ELISA for the proinflammatory cytokines TNF $\alpha$ and IL-1 $\beta$ as well as for the anti-inflammatory cytokine IL-10 (Elabscience, Wuhan, China). Briefly, up to $100 \mu \mathrm{l}$ supernatant was added into, with the specific antibody coated, wells of a 96-well microtitre plate, incubated, supernatant removed, specific biotinylated antibody added, incubated, washed, avidin-horseradish peroxidase conjugate added, incubated, washed, reaction solution added (not stated in the manual, probably $3,3^{\prime}, 5,5^{\prime}$ tetramethylbenzidine), acidic stop solution added, and the absorption at $\lambda=450 \mathrm{~nm}$ was determined for each well. The following samples were analysed: blank (medium + sample), mock control (diff. THP-1), negative control (diff. THP-1 + sample), positive control (diff. THP-1 + LPS), and test (diff. THP-1 + sample + LPS).

2.6. Statistical Analysis. Values are expressed as means \pm 1.96 * standard error of mean (1.96*SEM). Differences between groups were determined by one-way analysis of variance (ANOVA) using the program Origin 5.0.

\section{Results}

3.1. Cytotoxicity. Previously, cytotoxic effects of ILF on HeLa cells were reported [28]; therefore, in this study, cells of first contact with foodstuff, the intestinal cell line Caco-2, were analysed. Aloe gel extract with a high fibre content (ILF) already exhibited a cytotoxic effect with a $\mathrm{CC}_{50}=1.0 \mathrm{~g} / \mathrm{l}$ after $4 \mathrm{~h}$ of exposure (Figure 1). It should be highlighted that this value is below the recommended concentration of $5 \mathrm{~g} / \mathrm{l}$ for foodstuff. Aloe gel extract with a reduced content of fibres, that is, ILG, was not cytotoxic up to $15 \mathrm{~g} / \mathrm{l}$ (Figure 1). Neither by filtration nor by centrifugation the cytotoxicity of the ILF samples could be reduced; cytotoxic effects with $\mathrm{CC}_{50}=1.5 \mathrm{~g} / \mathrm{l}$ for ILF-f and $\mathrm{CC}_{50}=2.5 \mathrm{~g} / \mathrm{l}$ for ILF-c (Figure 1) could still be found at concentrations below the recommended $5 \mathrm{~g} / \mathrm{l}$ for ILF. Only a treatment of ILF with activated carbon (ILF-ac) reduced its cytotoxic effect considerably to $\mathrm{CC}_{50}>5.0 \mathrm{~g} / \mathrm{l}$ (Figure 1).

Overall, these results indicate that heated Aloe vera samples, when containing fibres (i.e., ILF), are cytotoxic and that this cytotoxic principle can be remediated by a treatment with activated carbon.

3.2. THP-1 Differentiation. Cell confluence affects the quantity of produced cytokines; thus, cells were observed microscopically for each sample to (a) prove the correct differentiation of THP-1 to macrophage-like cells and (b) estimate the confluence. After treatment with $1 \mu \mathrm{M}$ PMA for $3 \mathrm{~d}$, THP1 monocytes successfully differentiated into macrophagelike cells (Figure 2(a)). While THP-1 monocytes grew in suspension and thus were round, differentiated THP-1 cells were bigger and oval, grew adherent, and presented more granules. Those cells were subsequently treated with Aloe supplements and then challenged with $1 \mu \mathrm{g} / \mathrm{ml}$ LPS (Figure $3(\mathrm{a}))$. At low concentrations $(0.2 \times$ for WLP and ILG, and $0.005 \times$ for ILF) no alterations either in cell morphology or in staining behaviour by trypan blue could be observed (Figures $2(\mathrm{~b})-2(\mathrm{~d})$ ); that is, the cells were not inhibited by a cytotoxic effect of the sample itself.

The opposite effect could be seen at higher concentrations: at $1 \mathrm{x}(10 \mathrm{~g} / \mathrm{l}) \mathrm{WLP}$, confluence was reduced and the cells were stained bluer and rounded (dead) (Figure 3(b)). At $1 \times(5 \mathrm{~g} / \mathrm{l})$ ILF, the number of cells was clearly reduced and almost all cells were stained by trypan blue (Figure 3(d)). This result could be expected, as ILF has a $C_{50}=1.0 \mathrm{~g} / 1$ for HeLa [28] or Caco-2 (Figure 1). Even at 0.2× ILF, the cell number was reduced and many cells were rounded and stained blue (Figure 4(a)); this indicates that differentiated THP-1 are far more sensitive to ILF than HeLa or Caco2. However, when this sample was treated with activated carbon (ILF-ac), the same concentration was not toxic to differentiated THP-1 (Figure 4(b)). On the other hand, 1× (5 g/l) ILG did not reduce confluence, but several cells were stained blue (dead) (Figure 3(c)), which coincides with the low cytotoxicity against HeLa [29] and Caco-2 (Figure 1).

3.3. Immunomodulation. The immunomodulatory effect of different Aloe vera products was determined using differentiated THP-1 cells. The cells were first exposed to the different 


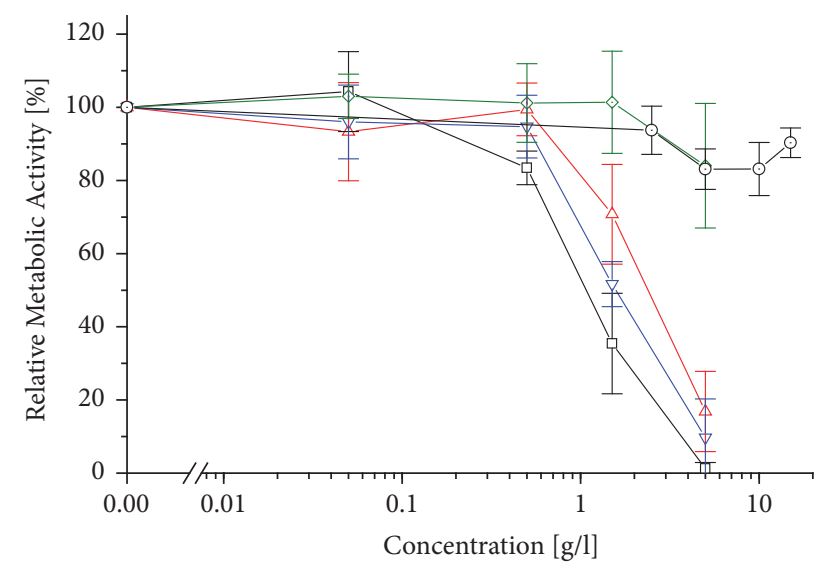

Figure 1: Metabolic activity (WST-1) of Caco-2 after $4 \mathrm{~h}$ exposure to differently treated Aloe-starting products and estimation of the cytotoxic concentration $\mathrm{CC}_{50}$ : ILG (dotted circle), ILF (square), ILFc (up triangle), ILF-f (down triangle), and ILF-ac (dotted diamond). Values are expressed as mean $\pm 1.96 * \operatorname{SEM}(n=4)$.

Aloe vera products for $1 \mathrm{~h}$ and then challenged with $1 \mu \mathrm{g} / \mathrm{ml}$ LPS. The cytokine release was measured after 3 and $24 \mathrm{~h}$ of exposure to the LPS. Figures 5, 6, and 7 show the changes of cytokine release caused by an Aloe-treatment respective to the cytokine release induced by LPS treatment alone. Although no clear changes could be observed after $3 \mathrm{~h}$, the effects were more obvious after $24 \mathrm{~h}$ : stimulation by LPS alone increased the release of the proinflammatory cytokines TNF $\alpha$ by $300 \%$ and IL- $1 \beta$ by even 29 times while the anti-inflammatory cytokine IL-10 increased up to 15 times compared to notchallenged THP-1 (Figures 5-7, black columns).

A treatment of differentiated THP-1 with low concentrations of WLP $(0.05 \times$ and $0.2 \times)$ increased the release of TNF $\alpha$ by 60 to $75 \%$, of IL- $1 \beta$ even by 10 to 20 times, and of IL-10 by 5 to 9 times (Figures 5-7, right grey columns). But when the differentiated THP-1 were challenged with LPS, then this WLP-treatment reduced TNF $\alpha$-release slightly by 20 to $33 \%$, IL- $1 \beta$-release remained stable, and the antiinflammatory cytokine IL-10 increased by 2 to 2.5 times (Figures 5-7, left grey columns). WLP at $1 \times$ reduced cell density of differentiated and challenged THP-1 (Figure 3(b)); nevertheless, the TNF $\alpha$-release still increased by $20 \%$, while WLP at $5 \times$ was cytotoxic and inhibited cytokine release (Figure 5, left grey columns).

Generally, at nontoxic concentrations, WLP stimulated the release of the proinflammatory cytokines TNF $\alpha$ and IL$1 \beta$ from differentiated THP-1, while on challenged THP-1 the proinflammatory cytokine release remained stable or was slightly reduced compared to untreated THP-1. The antiinflammatory cytokine IL-10 increased in both cases: challenged and not-challenged THP-1. Only at a nonphysiological and nontoxic concentration of $1 \times$ WLP, the TNF $\alpha$-release increased even of not-challenged THP-1.

ILG caused a similar behaviour on differentiated THP-1 like WLP, although less pronounced: at low concentrations (up to $0.2 \times$ ), the proinflammatory cytokines increased by 10 to $30 \%$ for TNF $\alpha$ and by 4 to 6 times for IL- $1 \beta$, while the antiinflammatory cytokine IL-10 increased but remained over all at a low level (Figures 5-7, right light grey columns). Again, when the differentiated THP-1 were challenged with LPS, up to $0.2 \times$ ILG reduced the liberation of proinflammatory cytokines: TNF $\alpha$ by 15 to $35 \%$ and IL-1 $\beta$ slightly by 5 to $15 \%$; on the other side, the anti-inflammatory cytokine IL10 increased by 2.2 to 2.4 times (Figures 5-7, left light grey columns). At $1 \times$, ILG increased TNF $\alpha$-release of differentiated THP-1 by 2 times (Figure 5, left light grey columns).

All in all, ILG has a similar immunomodulatory effect like WLP: at low concentrations, ILG stimulated the release of proinflammatory cytokines from not-challenged THP1, while on LPS challenged THP-1 the liberation of these cytokines was (slightly) reduced. The effect on the antiinflammatory cytokine was inverse: for not-challenged THP1 the values increased but remained on a low level and on LPS challenged THP-1 IL-10-release increased clearly.

As the ILF sample was already cytotoxic at a concentration $>0.2 \times$ (Figure $4(\mathrm{a})$ ), at this concentration, no cytokine release could be observed (Figures 5-7, rhombus patterned columns). At low concentrations (up to $0.05 \times$ ), ILF itself stimulated unchallenged but differentiated THP1 to increase the release of the proinflammatory cytokine TNF $\alpha$ by up to $40 \%$, while the liberation of IL- $1 \beta$ increased up to 12 times (Figures 5 and 6 , right rhombus patterned columns). Under this conditions, the liberation of the antiinflammatory cytokine IL-10 increased by 1.7 times (Figure 7, right rhombus patterned columns). When differentiated THP-1 were challenged with LPS the effect caused by ILF depended strongly on the used concentration: only at $0.005 \times$ a slight anti-inflammatory effect could be observed (IL10 increased by $23 \%$ ), but already at $0.05 \times$ this effect was inverted: IL- $1 \beta$ increased by $35 \%$ and IL-10 decreased by $40 \%$ (Figures 6 and 7, left rhombus patterned columns).

Finally, when the fibre containing sample was treated with activated carbon (ILF-ac) things changed: first of all, the sample was less cytotoxic (Figure 4) but at low concentrations $(0.05 \times)$ the capacity to stimulate the IL-10 release to similar values to those observed for ILG was also restored (Figure 7, left horizontal lined columns). Surprisingly, at the still noncytotoxic concentration of $0.2 \times$, ILF-ac already reduced IL10 release to approximately $85 \%$ (Figure 7 , right horizontal lined columns). This indicates that the ILF sample could be detoxified by an activated carbon treatment and was gaining some anti-inflammatory properties.

\section{Discussion}

In a previous work it was found that the inner leaf gel of Aloe vera (ILG) was not toxic for the human cervical cell line HeLa [29], whereas the inner leaf gel with a high fibre content (ILF) was cytotoxic for HeLa with a $\mathrm{CC}_{50}=1 \mathrm{~g} / \mathrm{l}$, which is even below the recommended concentration for human consumption [28]. In this study, those previous results could be confirmed with the more relevant human intestinal cell line Caco-2, cells which may be exposed to high concentrations of Aloe vera products after their ingestion. Both samples, ILG and ILF, were obtained from the same source (Aloe vera inner leaf gel); however, they are prepared in a very different manner. On one hand, the gel with its soluble polysaccharides 


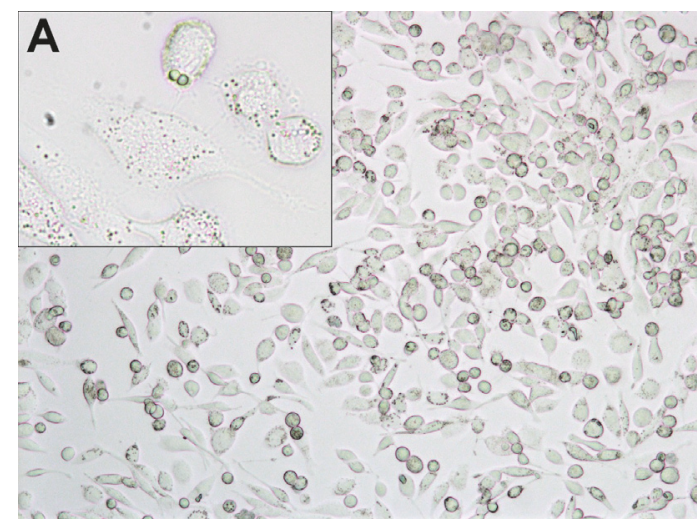

(a)

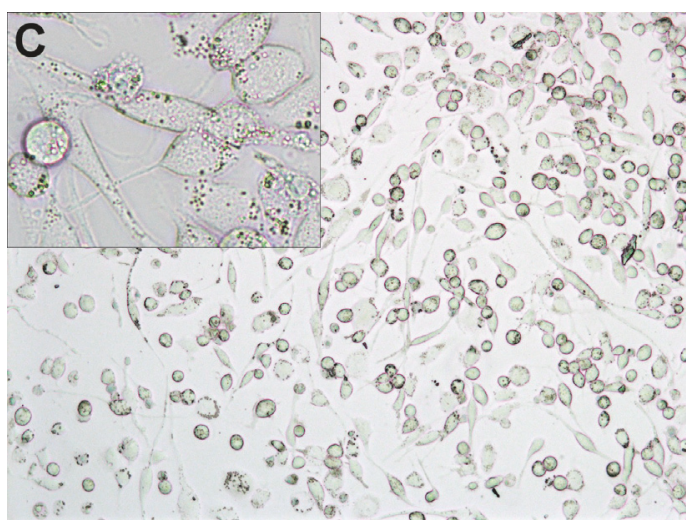

(c)

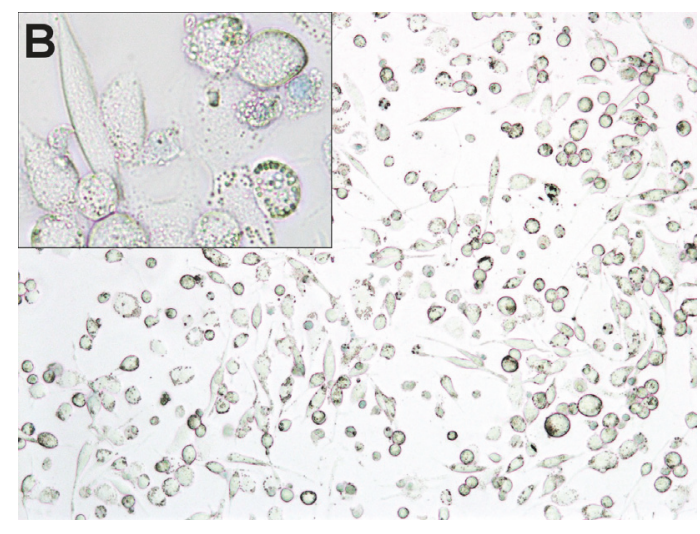

(b)

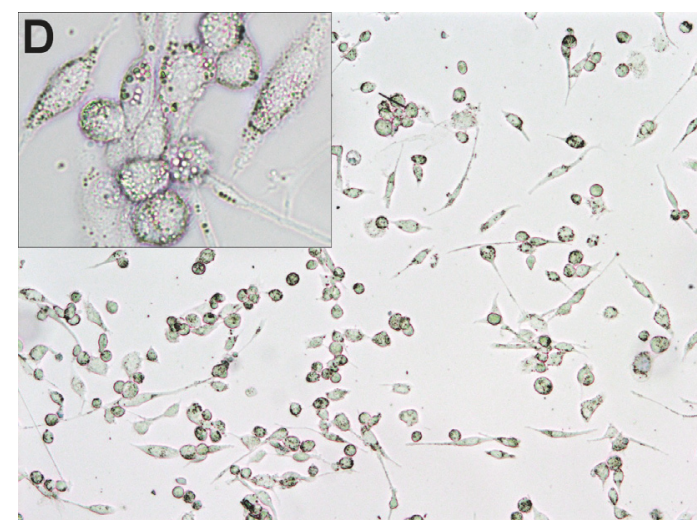

(d)

FIGURE 2: Trypan blue stained cells with compromised membrane are blue: differentiated THP-1 (a). Differentiated THP-1 challenged with $1 \mu \mathrm{g} / \mathrm{ml}$ LPS and additionally exposed to $2 \mathrm{~g} / \mathrm{l}(0.2 \times)$ WLP (b), $1 \mathrm{~g} / \mathrm{l}(0.2 \times)$ ILG (c), and $25 \mathrm{mg} / \mathrm{l}(0.005 \times)$ ILF (d), respectively.

was extruded for the ILG sample (thus has a low insoluble fibre content), treated with activated carbon and spray-dried at temperatures of about $60{ }^{\circ} \mathrm{C}$. On the other hand, the gel containing all the fibre and polysaccharide content was only dehydrated at $70-85^{\circ} \mathrm{C}$ for the ILF sample and hence not decolourized with activated carbon (a more detailed description of the sample preparation is given in [28]). Since both samples arise from the same source, the different applied treatments should explain the different cytotoxic effects. Now, the cytotoxic effect of ILF on Caco-2 $\left(C_{50}=1 \mathrm{~g} / \mathrm{l}\right)$ could not readily be reduced by centrifugation or filtration (Figure 1), but, by a treatment with activated carbon, the $\mathrm{CC}_{50}$ increased to $>5.0 \mathrm{~g} / \mathrm{l}$. These results indicate that the polysaccharides themselves are not cytotoxic. This coincides with the fact that acemannan isolated from $A$. vera is not cytotoxic to human gingival fibroblasts; in fact, at concentrations of 1 and $10 \mathrm{mg} / \mathrm{ml}$, it even stimulated cell growth [24]. The acemannan polymer can undergo a deacetylation process when exposed to temperatures above $70^{\circ} \mathrm{C}[27,30,31]$; but even deacetylated acemannan does not exhibit a cytotoxic effect [32].

The human monocyte cell line THP-1 is much more sensitive to Aloe-starting products than the intestinal line Caco-2: WLP and ILG were cytotoxic at $1 \times$ (i.e., $10 \mathrm{~g} / \mathrm{l}$ and $5 \mathrm{~g} / \mathrm{l}$, respectively) and ILF was cytotoxic even at $0.2 \times(1 \mathrm{~g} / \mathrm{l}$;
Figure 3); only at concentrations of $0.2 \times$ WLP, ILG, or $0.005 \times$ ILF did the cells grow normally (Figure 2 ). This coincides with results that $10 \%$ Aloe gel $(0.1 \times)$ reduced cell growth of THP-1 by only $20 \%$ [13]. However, under physiological conditions, it cannot be expected that blood cells like THP-1 would be exposed to such high concentrations as intestinal cells. Thus, relevant immunomodulatory effects should be expected at these or even lower concentrations.

There are three possible stimuli that induce an inflammatory response: infection, tissue injury or stress, and metabolic malfunction. For instance, the PAMP LPS is recognized by TLR4/MyD88, which activates the NF- $\kappa$ B signalling cascade and induces the synthesis of pro-IL-1 $\beta$ and NLRP3. Activation of the NLRP3-inflammasome can occur by extracellular ATP, recognized by the P2X7-receptor, leading to an efflux of cytosolic $\mathrm{K}^{+}$through pannexin-1: then NLRP3 associate with ASC and activate pro-caspase-1, which in turn activates the proinflammatory cytokine IL- $1 \beta$ by limited proteolysis $[33,34]$. As part of the inflammatory response, the release of IL- $1 \beta$ from infiltrating neutrophils induces the activation of several cell types such as macrophages, T-lymphocytes, epithelial, and endothelial cells and enhances the expression of further proinflammatory cytokines like IL- 6 and TNF $\alpha$ $[13,35]$. However, a prolonged synthesis of proinflammatory 


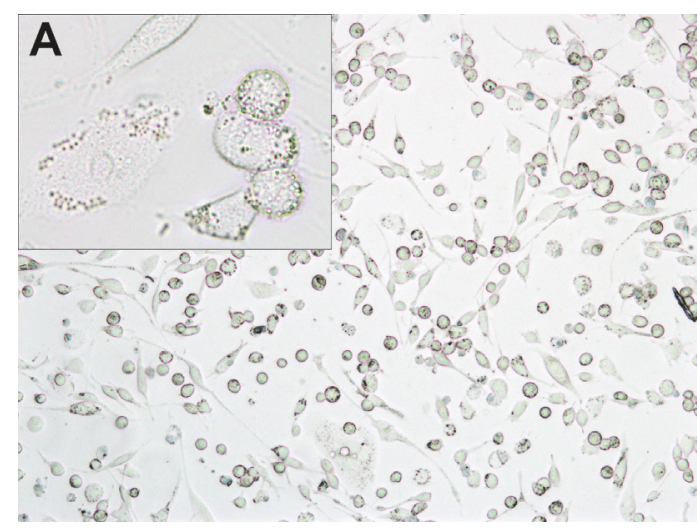

(a)

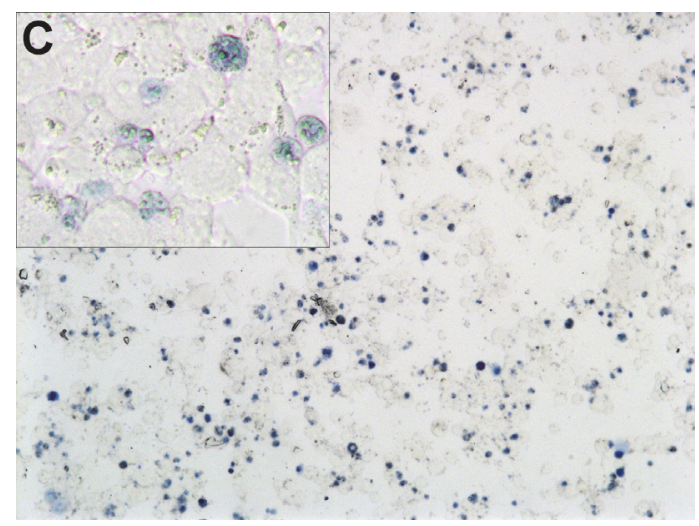

(c)

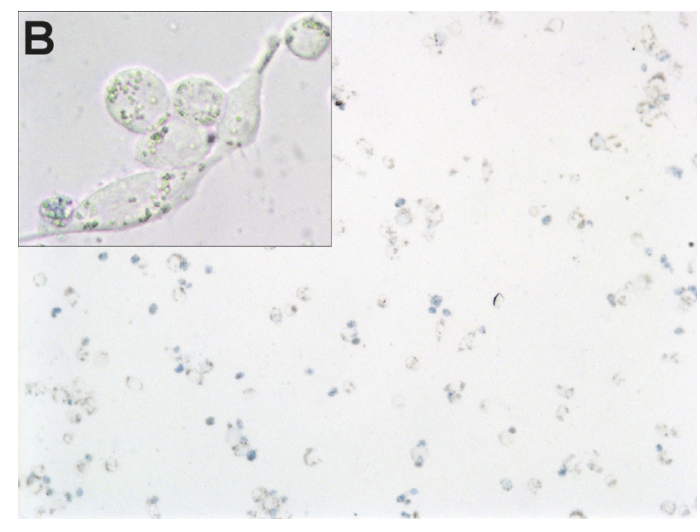

(b)

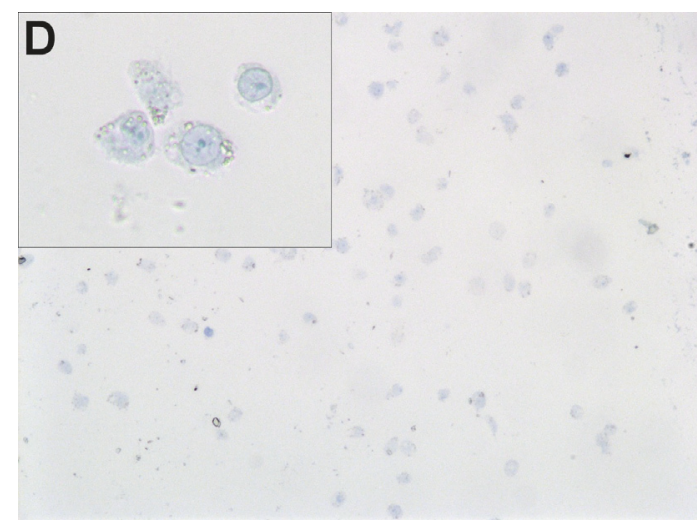

(d)

FIGURE 3: Trypan blue stained cells with compromised membrane are blue: differentiated THP-1 cells after being challenged for $24 \mathrm{~h}$ with $1 \mu \mathrm{g} / \mathrm{ml}$ LPS (a). Cells additionally exposed to $10 \mathrm{~g} / \mathrm{l}(1 \times)$ WLP (b), $5 \mathrm{~g} / \mathrm{l}(1 \mathrm{x}) \mathrm{ILG}(\mathrm{c})$, and $5 \mathrm{~g} / \mathrm{l}$ (1×) ILF (d), respectively.

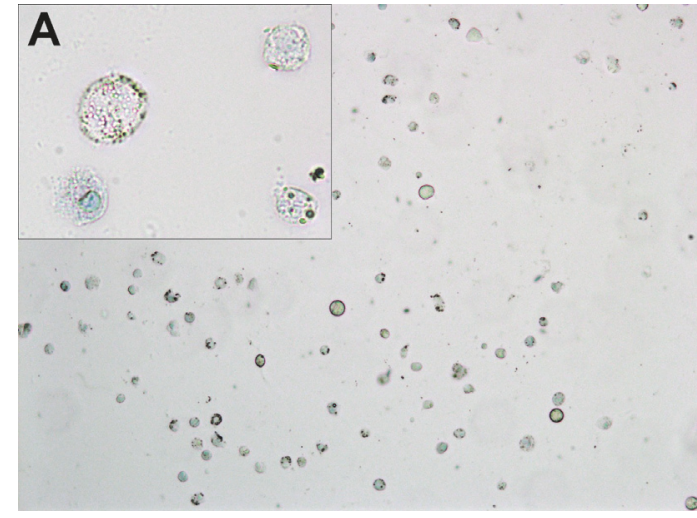

(a)

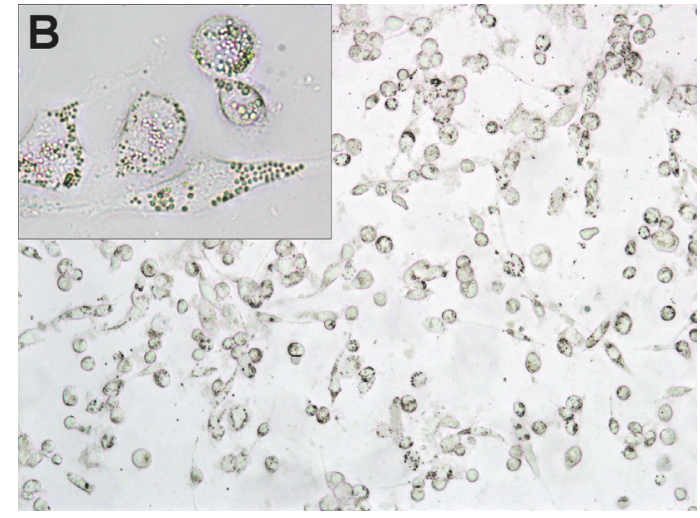

(b)

FIGURE 4: Trypan blue stained cells with compromised membrane are blue: differentiated THP-1 cells challenged with $1 \mu \mathrm{g} / \mathrm{ml} \mathrm{LPS}$ and additionally exposed to $1 \mathrm{~g} / \mathrm{l}(0.2 \times)$ ILF (a) and $1 \mathrm{~g} / \mathrm{l}(0.2 \times)$ ILF-ac, respectively.

cytokines contributes to a local or systemic inflammation, which may further develop into chronic diseases [36]; therefore, also their downregulation is required.

The polysaccharide fraction from Aloe inner gel, mainly acemannan, has been demonstrated to be immunomodulatory to monocytes and macrophages in several studies
[13, 21-23]. In agreement with the latter results, no significant changes in the liberation of proinflammatory cytokines (TNF $\alpha$, IL-1 $\beta$ ) were observed when differentiated and with LPS challenged THP-1 were exposed to samples with a low fibre and polysaccharide content (WLP, ILG) at low concentrations (up to $0.2 \times$ ): the release of TNF $\alpha$ was reduced 


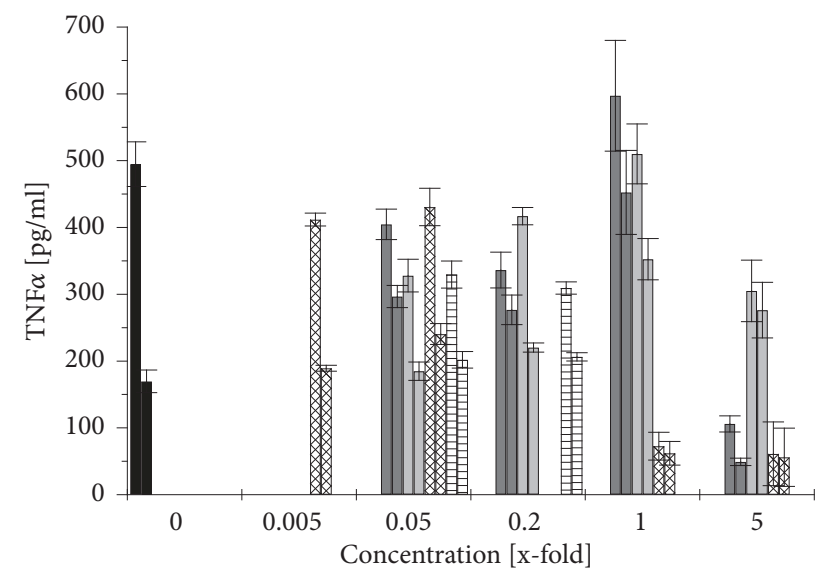

Figure 5: Changes in TNF $\alpha$ release after $24 \mathrm{~h}$ from differentiated THP-1 cells induced by a treatment with different Aloe vera products and LPS stimulation (left columns) compared to that without LPS stimulation (right columns). $1 \mathrm{x}$ refers to the recommended concentration for human consumption: control without Aloe vera treatment (black), WLP (grey), ILG (light grey), ILF (rhombus patterned), and ILF-ac (horizontally lined) columns. Values are expressed as mean $\pm 1.96 * \operatorname{SEM}(\mathrm{n}=3)$.

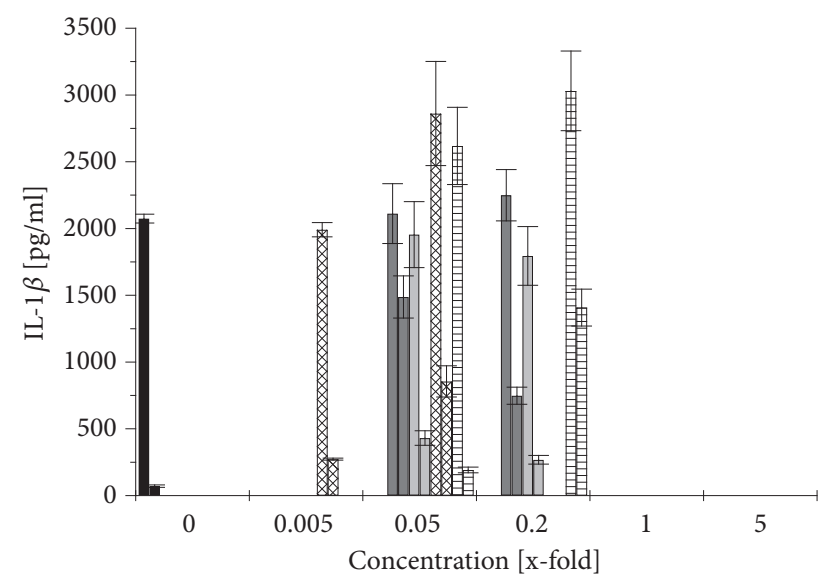

Figure 6: Changes in IL-1 $\beta$ release after $24 \mathrm{~h}$ from differentiated THP-1 cells induced by a treatment with different Aloe vera products and LPS stimulation (left columns) compared to that without LPS stimulation (right columns). $1 \mathrm{x}$ refers to the recommended concentration for human consumption: control without Aloe vera treatment (black), WLP (grey), ILG (light grey), ILF (rhombus patterned), and ILF-ac (horizontally lined) columns. Values are expressed as mean $\pm 1.96 *$ SEM $(n=3)$.

by 15 to $35 \%$ and of IL-1 $\beta$ did not change (Figures 5 and 6 , left grey and light grey columns). Budai et al. (2013) found that a commercial Aloe solution at $10 \%$ (which would correspond to $0.1 \times$ ILG) decreased TNF $\alpha$ and IL- $1 \beta$ release by $60 \%$ and $40 \%$, respectively, when differentiated THP-1 cells were challenged by LPS [13]. This may be explained by a downregulation of LPS-induced expression of NLRP3, pro-caspase 1, and P2X7R by the Aloe extract. However, here we report for the first time that, under these conditions, the anti-inflammatory cytokine IL-10 increased (Figure 7, left grey and light grey columns), which would support a general anti-inflammatory effect.

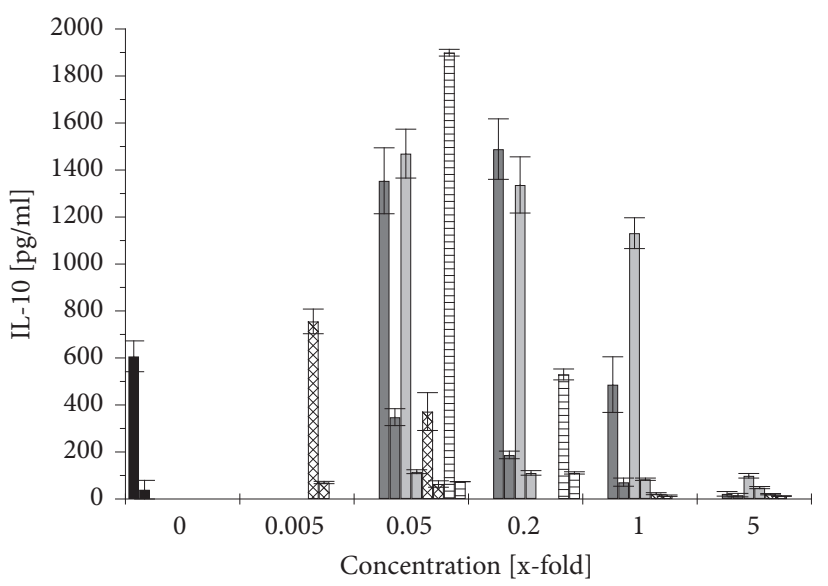

FIGURE 7: Changes in IL-10 release after $24 \mathrm{~h}$ from differentiated THP-1 cells induced by a treatment with different Aloe vera products and LPS stimulation (left columns) compared to that without LPS stimulation (right columns). $1 \mathrm{x}$ refers to the recommended concentration for human consumption: control without Aloe vera treatment (black), WLP (grey), ILG (light grey), ILF (rhombus patterned), and ILF-ac (horizontally lined) columns. Values are expressed as mean $\pm 1.96 * \operatorname{SEM}(\mathrm{n}=3)$.

This anti-inflammatory effect could also be demonstrated in Wistar rats with induced peritoneal Staphylococcus aureus infection: Aloe gel extract alone increased the liberation of IL$1 \beta$ and, as expected, infected animals exhibited increased IL$1 \beta$-levels. However, when the infected rats were treated with Aloe gel extract, the liberation of IL- $1 \beta$ decreased to normal values again [37].

The opposite effect was exhibited by the sample with the high fibre and polysaccharide content (ILF) at $0.05 \times$ : while the proinflammatory cytokine IL- $1 \beta$ increased slightly by $35 \%$ (Figure 6 , left rhombus patterned column), the anti-inflammatory cytokine IL-10 decreased by $40 \%$ (Figure 7, left rhombus patterned column). Similarly, Pugh et al. (2001) noted an increase of proinflammatory cytokine release (TNF $\alpha$, IL-1 $\beta$ ), when LPS challenged THP-1 cells were exposed to the $>500-\mathrm{kDa}$ polysaccharide fraction [23]. The mouse macrophage cell line RAW264.7 also increased proinflammatory cytokine release when in contact with acemannan [21] or with a purified polysaccharide fraction of $5-400 \mathrm{kDa}$ [22]. This would indicate that, apart from the cytotoxic effect of ILF samples, the immunomodulatory effects of ILF are not as desirable as those from ILG samples. Interestingly, when ILF at this concentration was treated with activated carbon (ILF-ac), not only was the cytotoxicity reduced but also the anti-inflammatory cytokine IL-10 increased by 3.1 times (Figure 7, left horizontal lined column) even surpassing the effects of ILG.

Aloe inner leaf gel products, treated with activated carbon (in order to reduce the aloin content) and spry dried at relatively low temperatures, exhibited more advantageous properties (low cytotoxicity, anti-inflammatory effect) than the recently introduced Aloe inner leaf gel with a high fibre content. Since these products were not treated with activated carbon, a cytotoxic principle is not removed and, by having high fibre content, may promote proinflammatory effects. 
Abbreviations

ASC: Apoptosis associated Speck-like protein containing CARD domain

ATCC: American Type Culture Collection

DMEM: Dulbecco's Modified Eagle Medium

FBS: $\quad$ Fetal Bovine Serum

FDA: $\quad$ Food and Drug Administration (USA)

IASC: International Aloe Science Council

ILF: Aloe inner leaf fibre powder

ILG: Aloe inner leaf gel powder

LPS: Lipopolysaccharide

NLRP3: Nucleotide-binding oligomerization domain, Leucine-rich repeat, and Pyrin domain-containing 3

NRU: Neutral red uptake

PAMP: Pathogen-associated molecular pattern

PBS: $\quad$ Phosphate buffered saline

RH: $\quad$ Relative humidity

RT: Room temperature

TLR: Toll-like receptor

WLP: Aloe whole leaf powder

WST: Water soluble tetrazolium

\section{Data Availability}

The raw data (from the photometer) as well as (also additional) photos used to support the findings of this study are available from the corresponding author upon request.

\section{Conflicts of Interest}

All authors manifest no conflicts of interest.

\section{Acknowledgments}

Gabriela Núñez-Jinez and Michelle N. Salazar Zúñiga were supported by a scholarship from the Consejo Nacional de Ciencia y Tecnología (CONACyT). We also thank Kurt Alejandro Maldonado Kanzler for revising the manuscript.

\section{References}

[1] H. C. Chen, W. T. Hsieh, W. C. Chang, and J. G. Chung, "Aloeemodin induced in vitro G2/M arrest of cell cycle in human promyelocytic leukemia HL-60 cells," Food and Chemical Toxicology, vol. 42, no. 8, pp. 1251-1257, 2004.

[2] E. J. Buenz, "Aloin induces apoptosis in Jurkat cells," Toxicology in Vitro, vol. 22, no. 2, pp. 422-429, 2008.

[3] Y. Cui, Q. Ye, H. Wang, Y. Li, W. Yao, and H. Qian, "Hepatoprotective potential of Aloe vera polysaccharides against chronic alcohol-induced hepatotoxicity in mice," Journal of the Science of Food and Agriculture, vol. 94, no. 9, pp. 1764-1771, 2014.

[4] G. Kaithwas, P. Singh, and D. Bhatia, "Evaluation of in vitro and in vivo antioxidant potential of polysaccharides from Aloe vera (Aloe barbadensis Miller) gel," Drug and Chemical Toxicology, vol. 37, no. 2, pp. 135-143, 2014.

[5] M.-C. Kang, S. Y. Kim, Y. T. Kim et al., "In vitro and in vivo antioxidant activities of polysaccharide purified from aloe vera
(Aloe barbadensis) gel," Carbohydrate Polymers, vol. 99, pp. 365-371, 2014.

[6] F. Nejatzadeh-Barandozi, "Antibacterial activities and antioxidant capacity of Aloe vera," Organic and Medicinal Chemistry Letters, vol. 3, article 5, 2013.

[7] L. Cellini, S. Di Bartolomeo, E. Di Campli, S. Genovese, M. Locatelli, and M. Di Giulio, "In vitro activity of aloe vera inner gel against Helicobacter pylori strains," Letters in Applied Microbiology, vol. 59, no. 1, pp. 43-48, 2014.

[8] M. Tanaka, E. Misawa, Y. Ito et al., "Identification of five phytosterols from aloe vera gel as anti-diabetic compounds," Biological \& Pharmaceutical Bulletin, vol. 29, no. 7, pp. 14181422, 2006.

[9] R. Kumar, B. Sharma, N. R. Tomar, P. Roy, A. K. Gupta, and A. Kumar, "In vivo evalution of hypoglycemic activity of Aloe spp. and identification of its mode of Action on GLUT-4 gene expression in vitro," Applied Biochemistry and Biotechnology, vol. 164, no. 8, pp. 1246-1256, 2011.

[10] H. F. Huseini, S. Kianbakht, R. Hajiaghaee, and F. H. Dabaghian, "Anti-hyperglycemic and anti-hypercholesterolemic effects of aloe vera leaf gel in hyperlipidemic type 2 diabetic patients: A randomized double-blind placebo-controlled clinical trial," Planta Medica, vol. 78, no. 4, pp. 311-316, 2012.

[11] B. Vázquez, G. Avila, D. Segura, and B. Escalante, "Antiinflammatory activity of extracts from Aloe vera gel," Journal of Ethnopharmacology, vol. 55, no. 1, pp. 69-75, 1996.

[12] F. Habeeb, G. Stables, F. Bradbury et al., "The inner gel component of Aloe vera suppresses bacterial-induced proinflammatory cytokines from human immune cells," Methods, vol. 42, no. 4, pp. 388-393, 2007.

[13] M. M. Budai, A. Varga, S. Milesz, J. Tozsér, and S. Benko, "Aloe vera downregulates LPS-induced inflammatory cytokine production and expression of NLRP3 inflammasome in human macrophages," Molecular Immunology, vol. 56, no. 4, pp. 471479, 2013.

[14] B. Ahluwalia, M. K. Magnusson, S. Isaksson, F. Larsson, and L. Öhman, "Effects of Aloe barbadensis Mill. extract (AVH200 ${ }^{\circledR}$ ) on human blood T cell activity in vitro," Journal of Ethnopharmacology, vol. 179, pp. 301-309, 2016.

[15] C. E. Turner, D. A. Williamson, P. A. Stroud, and D. J. Talley, "Evaluation and comparison of commercially available Aloe vera L. products using size exclusion chromatography with refractive index and multi-angle laser light scattering detection," International Immunopharmacology, vol. 4, no. 14, pp. 1727-1737, 2004.

[16] R. Capasso, A. A. Izzo, L. Pinto, T. Bifulco, C. Vitobello, and N. Mascolo, "Phytotherapy and quality of herbal medicines," Fitoterapia, vol. 71, Suppl. 1, pp. S58-S65, 2000.

[17] B. A. P. van Gorkom, E. G. E. De Vries, A. Karrenbeld, and J. H. Kleibeuker, "Review article: anthranoid laxatives and their potential carcinogenic effects," Alimentary Pharmacology \& Therapeutics, vol. 13, no. 4, pp. 443-452, 1999.

[18] M. D. Boudreau, P. W. Mellick, G. R. Olson, R. P. Felton, B. T. Thorn, and F. A. Beland, "Clear evidence of carcinogenic activity by a whole-leaf extract of Aloe barbadensis Miller (Aloe vera) in F344/N rats," Toxicological Sciences, vol. 131, no. 1, pp. 26-39, 2013.

[19] M. M. Dotzel, "Status of Certain Additional Over-the-Counter Drug Category II and III Active Ingredients," Final rule, DOCID:fr09my02-7; Docket No. 78N-036L; RIN 0910-AA01, Department of Health and Human Services (HHS) - Food and Drug Administration (FDA), 2002. 
[20] A. Femenia, E. S. Sánchez, S. Simal, and C. Rosselló, "Compositional features of polysaccharides from Aloe vera (Aloe barbadensis Miller) plant tissues," Carbohydrate Polymers, vol. 39, no. 2, pp. 109-117, 1999.

[21] L. Zhang and I. R. Tizard, "Activation of a mouse macrophage cell line by acemannan: The major carbohydrate fraction from Aloe vera gel," Immunopharmacology, vol. 35, no. 2, pp. 119-128, 1996.

[22] S.-A. Im, S.-T. Oh, S. Song et al., "Identification of optimal molecular size of modified Aloe polysaccharides with maximum immunomodulatory activity," International Immunopharmacology, vol. 5, no. 2, pp. 271-279, 2005.

[23] N. Pugh, S. A. Ross, M. A. ElSohly, and D. S. Pasco, "Characterization of aloeride, a new high-molecular-weight polysaccharide from Aloe vera with potent immunostimulatory activity," Journal of Agricultural and Food Chemistry, vol. 49, no. 2, pp. 10301034, 2001.

[24] P. Thunyakitpisal, V. Ruangpornvisuti, P. Kengkwasing, J. Chokboribal, and P. Sangvanich, "Acemannan increases NF- $\kappa$ B/DNA binding and IL-6/-8 expression by selectively binding Tolllike receptor-5 in human gingival fibroblasts," Carbohydrate Polymers, vol. 161, pp. 149-157, 2017.

[25] A. Bozzi, C. Perrin, S. Austin, and F. Arce Vera, "Quality and authenticity of commercial Aloe vera gel powders," Food Chemistry, vol. 103, pp. 22-30, 2007.

[26] R. Minjares-Fuentes, V. M. Rodríguez-González, R. F. González-Laredo, V. Eim, M. R. González-Centeno, and A. Femenia, "Effect of different drying procedures on the bioactive polysaccharide acemannan from Aloe vera (Aloe barbadensis Miller)," Carbohydrate Polymers, vol. 168, pp. 327-336, 2017.

[27] A. Femenia, P. García-Pascual, S. Simal, and C. Rosselló, "Effects of heat treatment and dehydration on bioactive polysaccharide acemannan and cell wall polymers from Aloe barbadensis Miller," Carbohydrate Polymers, vol. 51, no. 4, pp. 397-405, 2003.

[28] Z. López, G. Núñez-Jinez, G. Avalos-Navarro et al., "Antioxidant and cytotoxicological effects of Aloe vera food supplements," Journal of Food Quality, vol. 2017, Article ID 7636237, 10 pages, 2017.

[29] Z. López, P. Knauth, G. Avalos-Navarro et al., "Cytotoxic effects of Sábila (Aloe vera): Commercial products as food supplement," Journal of Chemical, Biological and Physical Science, vol. 4, Sec. C, pp. 47-54, 2014.

[30] X. L. Chang, C. Wang, Y. Feng, and Z. Liu, "Effects of heat treatments on the stabilities of polysaccharides substances and barbaloin in gel juice from Aloe vera Miller," Journal of Food Engineering, vol. 75, no. 2, pp. 245-251, 2006.

[31] V. M. Rodríguez-González, A. Femenia, R. F. González-Laredo et al., "Effects of pasteurization on bioactive polysaccharide acemannan and cell wall polymers from Aloe barbadensis Miller," Carbohydrate Polymers, vol. 86, no. 4, pp. 1675-1683, 2011.

[32] J. Chokboribal, W. Tachaboonyakiat, P. Sangvanich, V. Ruangpornvisuti, S. Jettanacheawchankit, and P. Thunyakitpisal, "Deacetylation affects the physical properties and bioactivity of acemannan, an extracted polysaccharide from Aloe vera," Carbohydrate Polymers, vol. 133, pp. 556-566, 2015.

[33] S. L. Cassel, S. Joly, and F. S. Sutterwala, "The NLRP3 inflammasome: a sensor of immune danger signals," Seminars in Immunology, vol. 21, no. 4, pp. 194-198, 2009.

[34] P. M. Chilton, C. A. Embry, and T. C. Mitchell, "Effects of differences in lipid A structure on TLR4 pro-inflammatory signaling and inflammasome activation," Frontiers in Immunology, vol. 3, Article ID 00154, 2012.

[35] C. Ciraci, J. R. Janczy, F. S. Sutterwala, and S. L. Cassel, "Control of innate and adaptive immunity by the inflammasome," Microbes and Infection, vol. 14, no. 14, pp. 1263-1270, 2012.

[36] C. A. Dinarello, "A clinical perspective of IL-1 $\beta$ as the gatekeeper of inflammation," European Journal of Immunology, vol. 41, no. 5, pp. 1203-1217, 2011.

[37] A. Altincik, F. Sönmez, Ç. Yenisey et al., "Effects of Aloe vera leaf gel extract on rat peritonitis model," Indian Journal of Pharmacology, vol. 46, no. 3, pp. 322-327, 2014. 


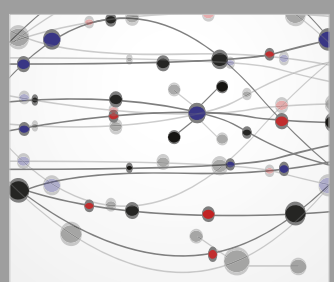

The Scientific World Journal
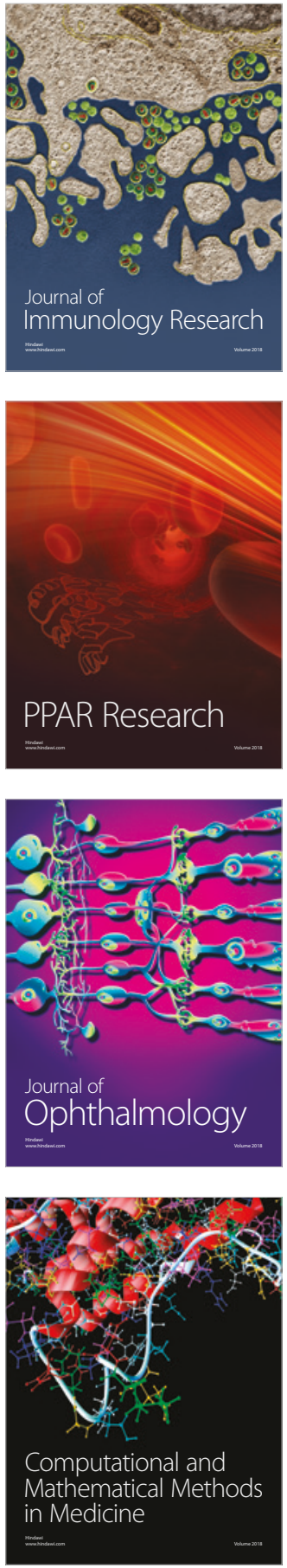

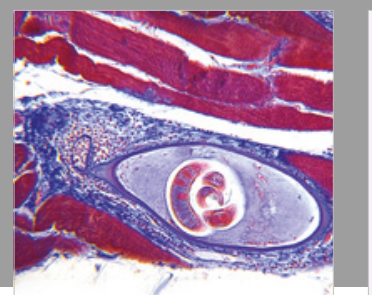

Gastroenterology Research and Practice

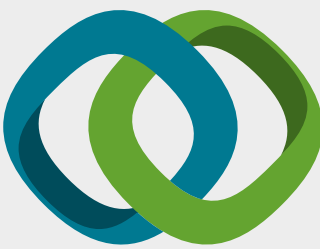

\section{Hindawi}

Submit your manuscripts at

www.hindawi.com
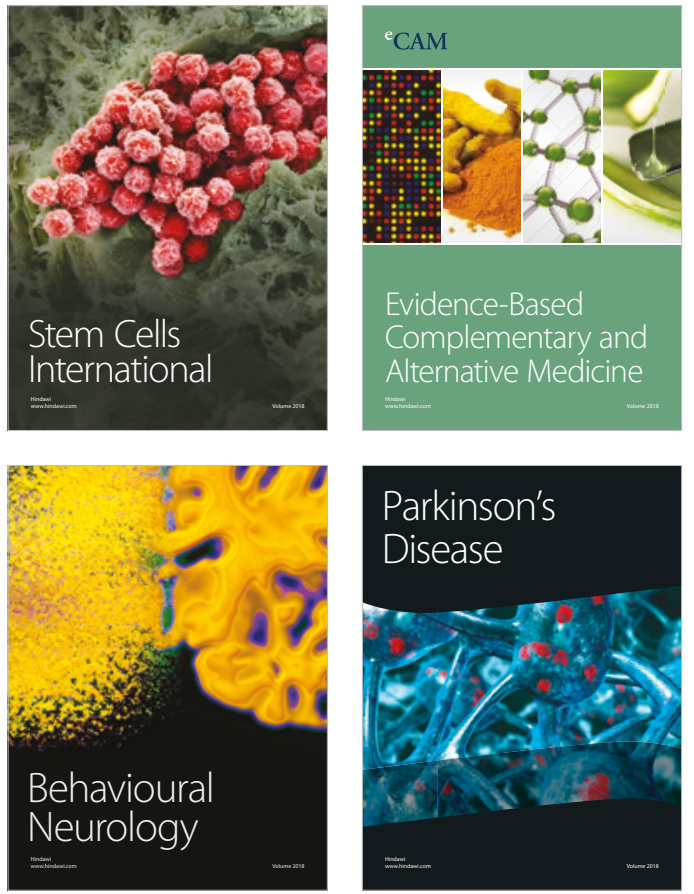

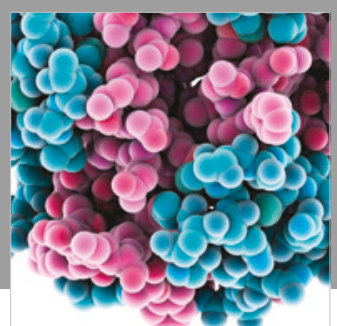

ournal of

Diabetes Research

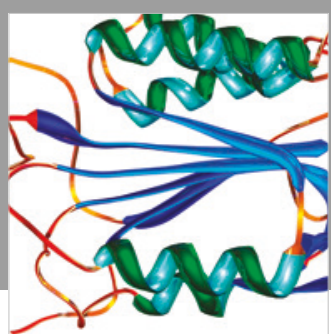

Disease Markers
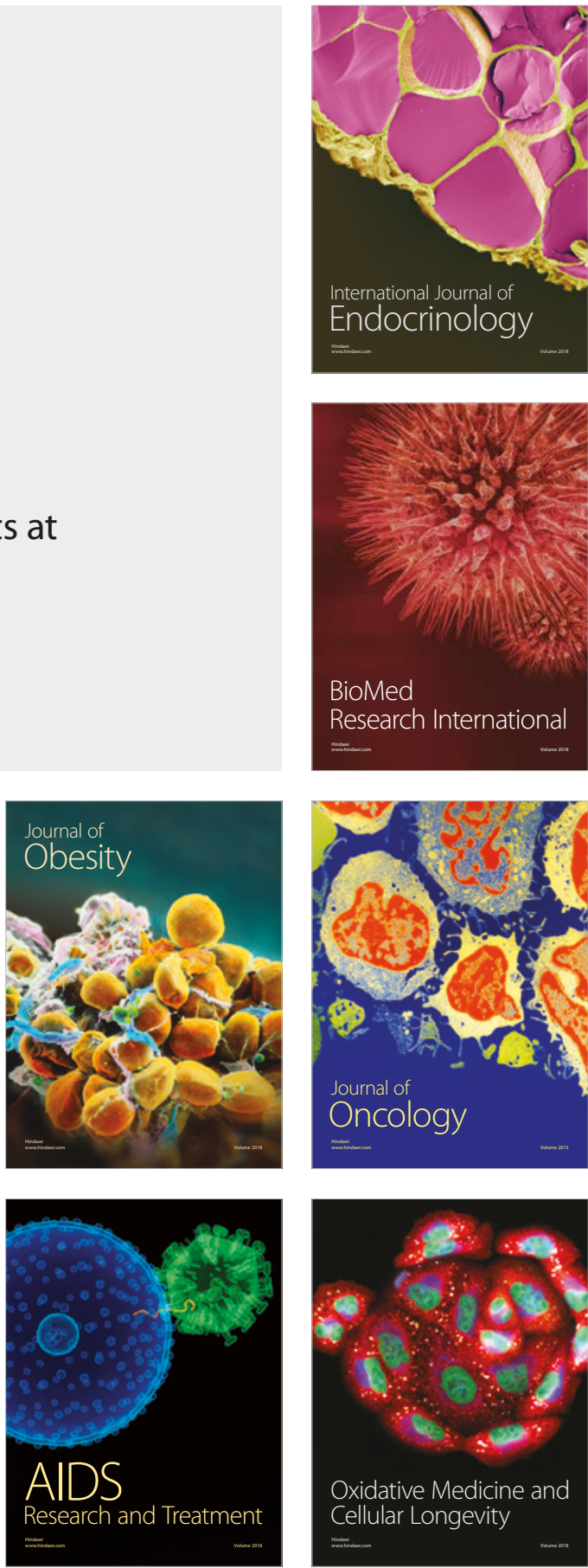